The research program of the Center for Economic Studies produces a wide range of theoretical and empirical economic analyses which serve to improve the statistical programs of the U.S. Bureau of the Census. Many of these analyses take the form of research papers. The purpose of the Discussion Papers is to circulate intermediate and final results of this research among interested readers within and outside the Census Bureau. The opinions and conclusions expressed in the papers are those of the authors and do not necessarily represent those of the U.S. Bureau of the Census. All papers are screened to ensure that they do not disclose confidential information. Persons who wish to obtain a copy of the paper, submit comments about the paper, or obtain general information about the series should contact Sang V. Nguyen, Editor, Discussion Papers, Center for Economic Studies, Room 1587, FB 3, U.S. Bureau of the Census, Washington, DC 20233

$(301-763-2065)$.

\title{
Costs, Demand, and Imperfect Competition as Determinants of Plant-Level Output Prices
}

\author{
By \\ Timothy Dunne* \\ Mark J. Roberts** \\ CES 92-5 June 1992
}




\section{Abstract}

The empirical modeling of imperfectly competitive markets has been constrained by the difficulty of obtaining micro data on individual producer prices, outputs, and costs. In this paper we utilize micro data collected from the 1977 Census of Manufactures to study the determinants of plant-level output prices among U.S. bread producers. A theoretical model of short-run price competition among plants producing differentiated products is used to specify reduced-form equations for each plant's price and output. Estimates of the reduced-form equations indicate that the main determinants of both the plant's output level and output price are the plant's own cost variables, particularly its capital stock and the prices of material inputs. The number of rival producers faced by the plant, the production costs of these rivals, and the demand conditions faced by the plant play no role in price or output determination. The results are not consistent with either oligopolistic competition or monopoly behavior, but rather are consistent with price-taking behavior by individual producers combined with output quality differentials across producers.

Keywords: price competition, cost structure, baking industry

\footnotetext{
${ }^{*}$ Center for Economic Studies, U.S. Bureau of the Census

${ }^{* *}$ Department of Economics, The Pennsylvania State University
}

The authors are very grateful to Mike Baye, Keith Crocker, Timothy Hannan,

John Siegfried, Dan Sullivan, Leonard Weiss, and participants at a conference at the WZB Berlin and at a seminar at the U.S. Census Bureau for helpful comments and discussion. Any opinions, findings, or conclusions expressed here are those of the authors and do not necessarily reflect the views of the Census Bureau. Forthcoming in Empirical studies in Industrial Organization: Essays in Honor of Leonard W. Weiss, David Audretsch and John Siegfried (eds.), Kluwer Academic Publishers. 


\section{Introduction}

For approximately the last forty years industrial organization economists have undertaken empirical studies to determine if an increase in the number of producers results in more competitive market outcomes. In recent years a number of empirical studies, many under the inspiration and guidance of Leonard Weiss, have focused directly on the relationship between the price of output in a market and the number or size distribution of competitors. The main finding of this literature is clearly stated by Schmalensee (1989, p.988); "In cross-section comparisons involving markets in the same industry, seller concentration is positively related to the level of price." 1

The methodology used in these price-concentration studies differs from that used in the earlier profits-concentration literature. In particular, each study generally focuses on a specific industry and uses observations from either different time periods or different geographic markets. Because they do not rely on across-industry differences in market structure to identify competitive effects, their inferences about competition are less likely to be biased by the across-industry differences in technology that are difficult to fully control for. Direct studies of output prices also avoid the substantial problems of accurately measuring economic profit. ${ }^{2}$

When examining the relationship between price and market structure it is important to control for variation in production cost across observations. In the majority of studies an observation is a local geographic market, often a

1 In his summary of the price-concentration studies, Weiss reports that, across 212 data sets, 62.8 percent reveal a statistically significant positive relationship between producer concentration and market prices. Another 24.8 percent of the data sets are characterized by a positive, but not statistically significant, relationship (Weiss (1989), p. 267). Many of the studies in this literature are also summarized in Schmalensee (1989), Bresnahan (1989), and Werden (1991).

2 See Weiss (1989), p.5-7 and Schmalensee (1989), p.960-966 for summaries of the measurement issues. 
city or SMSA, and the price and cost variables are constructed as an average for the market. ${ }^{3}$ What is lost in this type of data is any information on the extent of cost or output price heterogeneity among the producers in the market. ${ }^{4}$ However, the presence of within-market producer heterogeneity can affect the observed relationship between the average output price and market structure. For example, if all firms produce a homogeneous output under conditions of decreasing returns to scale, but differ in their factor prices or efficiency levels, then market price is determined by the costs of the least efficient firm. In contrast, the distribution of output will be skewed toward the low-cost producers thus generating higher concentration than would be observed if there was no cost heterogeneity. A market price that is positively correlated with concentration could result if the degree of cost heterogeneity varied across markets. ${ }^{5}$

As new micro data sources have become available to industrial organization economists, one of the clear facts to emerge is the large degree of within-industry producer heterogeneity. In general, it is desirable to recognize this heterogeneity when modeling output price determination within a market. This paper will utilize data on individual manufacturing plants from the 1977 U.S. Census of Manufactures and control for producer heterogeneity in a way that is not possible with market-level data. We will examine the relationship between the output price charged by the plant, the plant's own

3 A related group of studies including Garber and Klepper (1980, 1986) and some papers in Weiss (1989) rely on across-industry data but focus on changes in prices and market structure over time.

4 Borenstein (1989) and Borenstein and Rose (1989) are two studies that specifically analyze the extent of output price heterogeneity. They examine variation in airline fares, both across firms and across passengers within the same firm, on individual city-pair routes.

5 This is similar to Demsetz's (1973) argument that cost heterogeneity or other firm-level efficiency differences are the basis for the positive correlation between concentration and average profitability. 
production costs and demand variables, and the number and costs of rival producers within the plant's service area.

As with the studies in the price-concentration literature, we will focus on a single industry in which producers sell in geographically dispersed markets. Our application is the bread industry. Because of the need for producers to deliver the product quickly, the geographic area served by each plant is generally small. This, combined with the fixed cost of operating a distribution network, suggests that there is some possibility for local market power. In addition, the Census of Manufactures data reveal a substantial amount of output price dispersion across plants, yet both the product and the technology are fairly homogeneous. This suggests that differences in local demand conditions and market competition may play an important role in explaining price variation among producers in this industry. ${ }^{6}$

The empirical model we estimate consists of reduced-form equations for a plant's output price and output level when the plant operates in an oligopolistic market. The empirical results indicate that the important determinants of both the plant's output level and output price are the plant's own costs, particularly its capital stock, and the prices of important material inputs. We find that the number of rival producers, the production costs of these rivals, and the demand conditions faced by the plant play no role in price or output determination. The results are not consistent with either oligopolistic competition or monopoly behavior by bread producers.

In the next section of this paper we outline a simple model of short-run oligopolistic competition that implies a reduced-form regression model similar to that used in many price-concentration studies. In the third section we

6 In our sample of 624 U.S. plants that manufacture bread the mean price is 34.0 cents per pound in 1977 and the standard deviation is 12.0 cents per pound. Abbott (1991) also reports a substantial degree of output price dispersion across U.S. manufacturing plants, even for products defined at the seven-digit SIC level. 
discuss the plant-level Census data and the construction of the plant's

service area. The empirical results are presented and discussed in the fourth section.

\section{A Reduced-Form Model of Short-Run Price Competition}

In this section we outline a simple model of short-run price competition in an oligopolistic market that implies a relationship between the price charged by a producer, demand conditions, and the cost characteristics of his rivals. An empirical model is then developed to examine if the price and output decisions of individual producers in the U.S. bread industry are systematically related to the number of rivals they face or their rival's production costs.

We begin with a short-run framework, in which the number of plants and each plant's size are taken as given, and use it to describe the plant's choice of output price. ${ }^{7}$ Suppose that plant i has a fixed capital stock of $K_{i}$. Short-run production costs for plant $i$ can be represented by the variable cost function

$$
V C_{i}=V C_{i}\left(K_{i}, W_{i}, q_{i}, A_{i}\right)
$$

7 The difference between long-run and short-run competition is often modeled with a two-stage framework. First, a group of potential entrants decide whether to enter a market and what size plant to build. This entry and capacity decision depends upon the sunk cost of constructing production and distribution facilities and the expected nature of post-entry competition. In the second stage each firm chooses price or output with its decision depending upon its production costs and the cost conditions of the other first-stage entrants. The model used here corresponds to the second stage of this process. 
where $W_{i}$ is a vector of fixed prices for all variable inputs, such as labor and materials, $\mathrm{q}_{i}$ is the plant's output level, and $\mathrm{A}_{i}$ is an index of technology for plant $i$. The variable cost function represents the minimum expenditure on variable inputs needed to produce the output $\mathrm{q}_{i}$, given the plant's capital stock and technology. It is increasing in variable input prices and decreasing in the plant's capital stock.

On the demand side each plant produces a differentiated product with the outputs of other producers being imperfect, but possibly close, substitutes. It is assumed that plant $i$ faces $\mathrm{N}^{-1}$ other existing plants that sell in the geographic area that is served by plant $i$. The demand curve faced by plant i is

$$
q_{i}=q_{i}\left(P_{i}, P_{i}^{R}, X_{i}\right)
$$

$P_{i}$ is the price charged by plant $i, P_{i}^{R}$ is the vector of output prices charged by its N-1 rivals, and $\mathrm{X}_{i}$ is a set of exogenous variables that shift the plant i demand curve. This specification is sufficiently general to allow changes in rival prices or the number of rivals to alter both the level of demand and the own-price elasticity of demand for plant i. In general we expect that as the number of rivals increases, or as $\mathrm{P}_{i}$ and the elements of $\mathrm{P}_{i}^{\mathrm{R}}$ become more similar, plant i's demand elasticity will increase. ${ }^{8}$

8 In this study we rely on a model of product differentiation and price choice because of the presence of output price variation in the plant-level data we utilize. In contrast, most of the empirical price-concentration studies assume that the firms produce a homogeneous product. In particular, the Cournot model, with its prediction that market price and the average industry markup vary positively with the Herfindahl index, provides the implicit justification for most of these studies. Further justification for the use of the cournot model in a homogeneous output market is provided by 
Using (1) and (2), short-run profit for plant i can be written as

$$
A_{i}=P_{i} q_{i}\left(P_{i}, P_{i}^{R}, X_{i}\right)-V C_{i}\left(K_{i}, W_{i}, q_{i}\left(P_{i}, P_{i}^{R}, X_{i}\right), A_{i}\right) .
$$

In the short run each of the $\mathrm{N}$ plants in the market is assumed to simultaneously choose its own price to maximize its short-run profits. The necessary conditions for a Nash equilibrium are

$$
\frac{\partial \mathrm{A}_{i}}{\partial P_{i}}=\left(\mathrm{P}_{i}, \mathrm{P}_{i}^{\mathrm{R}}, \mathrm{X}_{i}, \mathrm{~K}_{i}, \mathrm{~W}_{i}, \mathrm{~A}_{i}\right)=0 \quad i=1,2, \ldots, N \text {. }
$$

Each plant maximizes its profits given the prices charged by its rivals. The $\mathrm{N}$ profit-maximizing conditions (eq. 4) and the $\mathrm{N}$ demand curves (eq. 2) faced by the plants describe the set of short-run profit-maximizing prices and output levels for the $\mathrm{N}$ producers.

This structural model implies a reduced-form equation for each plant's price and output. The arguments of the reduced-form equations are the capital stock, variable input prices, technology index, and demand shifters for all the producers. Dividing these variables into two groups, those that pertain to plant $i$ and those that pertain to all of its $\mathrm{N}^{-1}$ rivals, allows the reduced-form equations for plant i to be written as

$$
P_{i}=f\left(X_{i}, K_{i}, W_{i}, A_{i}, X_{i}^{R}, K_{i}^{R}, W_{i}^{R}, A_{i}^{R}\right)
$$

Kreps and Schenkman (1983) who show that a process of two-stage competition in capacities and then prices can lead to Cournot outcomes. 
(5)

$$
q_{i}=f\left(X_{i}, K_{i}, W_{i}, A_{i}, X_{i}^{R}, K_{i}^{R}, W_{i}^{R}, A_{i}^{R}\right) \text {. }
$$

The variables with $R$ superscripts are vectors over all of plant i's rivals. The reduced-form equations illustrate, not surprisingly, that in a general model of oligopolistic competition each producer's price and output depend upon the demand and cost characteristics of all producers in the market. As a result, the reduced-form equations summarize a very general process of oligopolistic price determination.

In this model all interdependence among producers is embedded in the plant demand functions and rival variables matter because they can affect plant i's demand elasticity and markup. Therefore a finding that rival firm demand or cost variables do not enter the reduced-form price and quantity equations implies a rejection of interdependence through the demand functions. Two very different forces could lead to an absence of interdependence. In the first case interdependence could be absent because each plant is an independent monopolist facing its own demand curve that does not depend on rival firm prices. In this case, while the reduced-form regressions will not depend on the rival variables $\left(X_{i}^{R}, K_{i}^{R}, W_{i}^{R}, A_{i}^{R}\right)$ they will depend on the plant's own demand shifters $X_{i}$ as well as its cost variables.

A second reason why rival variables may not matter is that each plant faces a sufficiently large number of substitute products that the demand elasticity for its own product is very large. In effect, if each plant faces a horizontal inverse demand curve for its own output then rival cost conditions will not be determinants of the plant's price. In this case the price heterogeneity observed across plants should reflect only differences in the quality of the product and not differences in markups resulting from variation in demand elasticities. If an industry's technology is 
characterized by low entry costs for each quality level then highly-elastic plant-level demand curves are probably the industry norm. ${ }^{9}$ The goal of the empirical model is to estimate the reduced-form price and quantity equations and test if demand characteristics or rival plant characteristics are an important determinant of a plant's price and output level. The empirical issue is whether sets of variables implied by monopoly or oligopolistic competition enter into the reduced-form price and output equations.

An alternative methodology for identifying the presence of interdependence among producers in a market has been developed by Panzar and Rosse (1987). They use comparative static techniques to derive the effect of exogenous input price changes on firm revenue and show that, in a homogeneous output market, the sum of the elasticities of revenue with respect to input prices will vary with the nature of competition among firms. This can allow a researcher to distinguish among monopoly, price-taking behavior in the short run, long run equilibrium in a competitive market, monopolistic competition, and certain types of oligopolistic competition by examining the coefficients on input prices in a reduced-form revenue equation. A difficulty with applying this methodology in a market where producers have heterogeneous costs and differentiated outputs is that the sign of comparative static effects cannot generally be derived without placing a great deal more structure on the demand side of the model. ${ }^{10}$ As a result, we prefer to specify reduced-form

\footnotetext{
9 This implies that it is differences in entry costs or restrictions, and not differences in the number or size distribution of exisiting producers, that result in variation in markups across geographic markets.

10 Dixit (1986) derives comparative static results for price, output, and profit in a duopoly with differentiated products and heterogeneous costs. He shows, among other things, that a positive shock to the marginal profits of one firm will raise that firm's output and lower rival output. The effects on both firms' prices are indeterminate.
} 
equations for a general oligopoly model and then test exclusion restrictions on the form of the equation. ${ }^{11}$

In order to have sufficient variation in the characteristics of demand and rival firms we will examine an industry in which markets are local rather than national. The bread industry in the United States is composed of a large number of plants that each serve a fairly small geographic area. As a result, the environment in which each plant operates, as measured by demand conditions and the number and cost characteristics of rivals, can vary across individual plants and this cross-section variation in local market conditions will be used to estimate the reduced-form price and quantity equations.

The reduced-form equations imply that each plant's price and output depend upon the cost characteristics, such as factor prices and capital stocks, of each plant that it competes with. Empirically, it will be necessary to aggregate over each plant's competitors in order to develop summary measures of the group of rivals faced by each plant. In the next section we summarize the data and discuss measurement of each plant's service area and the characteristics of its competitors.

\section{Data and Measurement Issues}

Our data set consists of observations on individual bread manufacturing plants that were collected as part of the U.S. Census of Manufacturers in 1977. The bread industry (SIC 2051) includes eight five-digit product categories. We focus on the plants that produce in two of these categories; bread (20511) and rolls (20512). Together these two product categories

11 Panzar and Rosse (1987) also note that restrictions on the explanatory variables of reduced-form regressions can be used to distinguish price-taking behavior in the long run from monopoly. The former implies that demand variables do not enter the reduced-form equation. Bresnahan (1989, p.10351037) also discusses exclusion restrictions on reduced-form revenue equations. 
account for 65.0 percent of the value of shipments of the four-digit industry in 1977. Our data set consists of observations on 681 plants. These plants represent approximately 22 percent of the total number of plants in the four-digit industry in 1977 but they are responsible for 88 percent of the total quantity of bread produced and 84 percent of the quantity of rolls. ${ }^{12}$ Of these plants, 91.6 percent manufacture bread and 85.2 percent produce rolls. Joint production of both products occurs in 76.8 percent of the sample plants.

The evolution of the structure of the U.S. bread industry is summarized in Sutton (1991, p.409-411). The industry is composed of nine national chains and a larger number of regional chains that operate multiple plants. Combined with this is a group of single-plant producers. In our dataset 69.5 percent of the plants are owned by multi-plant firms. During the 1970's two major national chains expanded significantly, often by acquiring local bakers. This expansion phase, which covers the year of our data, was often accompanied by aggressive price competition that resulted in charges of predatory pricing in some local markets. ${ }^{13}$

The purpose of the empirical model is to identify the determinants of each plant's price and output level. We will estimate separate reduced-form regressions for the bread and roll product categories. The dependent variable

12 The data set was limited to plants that reported detailed breakdowns of their input use because this was necessary to measure the plant's input prices. These tend to be the larger manufacturing plants.

13 In constrast to this, accusations of price-fixing have been fairly common in this industry. Between 1951 and 1980 the Justice Department filed 22 price-fixing cases against groups of bread manufacturers (Block and Clabault (1981)), although the number of cases diminished in the 1970's relative to the two earlier decades. Using city-level data for the period 1964-1976, Block, Nold and Sidak (1981) find evidence that increased antitrust enforcement reduced the markups charged by bread producers. There were no price-fixing cases filed that suggest illegal pricing behavior in 1977, the year of our data. However, if price-fixing was occuring, and the ability to successfully collude increased with a reduction in the number of competitors, then, after controlling for cost differences, prices should be higher in markets with few competitors. 
in the price regressions will be the average price of bread $\left(P_{B}\right)$ or rolls $\left(P_{R}\right)$ sold by the plant. It is constructed by dividing the plant's revenue in the product category by the physical quantity, measured in pounds, of bread or rolls produced. These output prices are thus unit-value indexes for each of the five-digit products. The quantity reduced-form regressions use the physical quantity of bread $\left(q_{B}\right)$ or rolls $\left(q_{R}\right)$ as the dependent variable. The dependent variables in the regressions are the plant's cost variables, as well as the demand and cost characteristics of rivals in the plant's output market. The basic cost information for each plant includes the plant's capital stock, prices of important inputs, and measures of age and multi-product production. The plant's capital stock (K) is defined as the sum of the book value of structures and equipment. The average hourly wage rate of production workers $\left(W_{P}\right)$ is measured as the expenditure on salaries plus benefits for production workers divided by their total hours of work. The annual wage of nonproduction workers $\left(\mathrm{W}_{\mathrm{NP}}\right)$ is measured as the expenditure on salaries plus benefits for nonproduction workers divided by the number of nonproduction workers. The price of flour $\left(W_{F}\right)$ paid by the plant is constructed by dividing the expenditure on flour by the physical quantity consumed. The price of electricity $\left(W_{E}\right)$ is measured as the ratio of the expenditure on electricity to the physical quantity consumed. The price of other material inputs $\left(W_{M}\right)$ is measured as a share-weighted average of the prices the plant pays for several other inputs including yeast, sugar, and fat and oil. Each of these prices is the ratio of the plant's expenditure on the input to the physical quantity consumed. It is important to emphasize that all input prices are plant-specific.

Several additional variables are included to control for plant characteristics that may be cost related. A plant's age is included as a 
proxy for the plant's efficiency level or the vintage of its capital stock. ${ }^{14}$ A dummy variable is included to distinguish plants owned by multi-plant firms. If there are any cost economies or diseconomies arising from multi-plant operation, such as due to transfers in knowledge, managerial skills, or production information, this variable will proxy for it. Finally, it is necessary to control for differences in the mix of outputs among the plants. Even for what seems like a fairly homogeneous product, there is room for interplant product differentiation. In general, each plant produces a range of outputs, including specialty bread products as well as basic white bread. It is important to note that if plants produce different quality products, or if the bundle of different bread products varies across plants, this will result in plant-level output price heterogeneity even if the plant acts as a price-taker in the market for each of its products. A set of dummy variables is included to identify which of the seven-digit bread and roll products are produced in each plant. ${ }^{15}$ In the reduced-form equation for the price of bread (rolls) the dependent variable is the average price measured at the five-digit level. The dummy variables for the seven-digit bread (roll) products control for compositional differences in the bundle of seven-digit bread (roll) products across plants. The dummy variables for the roll (bread) products in

14 Dunne, Roberts, and Samuelson (1989) find that plant age is an important correlate of both plant failure rates and growth rates in a way that is consistent with efficiency differences across plants and a process of market selection.

15 The five seven-digit bread products included in SIC 20511 are: white pan bread, white hearth bread including French and Italian, wheat bread, rye and pumpernickel, and other variety bread including raisin and potato. The six roll products included in SIC 20512 are: hamburger and hot dog rolls, brown and serve rolls, english muffins, hearth rolls, other bread type rolls, and stuffing and croutons. 
the bread (roll) equation capture any price effects resulting from economies of scope in production. ${ }^{16}$

The theoretical model predicts that in an oligopolistic market the plant's price and output will depend on the characteristics of the other plants that it competes with. In any empirical study it is necessary to define the market that is relevant. Most empirical studies in this literature define a specific geographic area such as an SMSA and then measure the average price over all producers, assuming the output is homogeneous, within the defined area. Once a geographic area is defined then producers who lie just outside this area, and who may sell or be able to sell in this area if output prices rose, are assumed to have no effect on observed price. Rather than define a specific geographic area as the output market to study, we recognize that in the Census data the output price we observe for each plant is the average output price over all sales in whatever geographic area the plant serves. If plants are interdependent then it is the characteristics of the other plants that could serve all or part of the same area that are relevant for explaining the plant's output price. As a result, to explain output price variation at the plant level we do not want to measure the extent of competition within a given city or SMSA, but rather the competition faced by each plant in the area it services.

In general most plants serve a fairly small geographic area. According to the 1977 Census of Transportation, 70 percent of all bread is shipped less than 100 miles and 85 percent is shipped less than 200 miles. We define two possible service areas for each plant. The primary service area consists of the area within a 50 mile radius of the plant while the secondary service area

16 If there are economies of scope in the production of bread and rolls then plants that produce rolls will have lower marginal costs for bread. The mix of outputs to produce is ultimately a decision variable for the plant. We ignore this issue here and treat the decision of which seven-digit products to manufacture as predetermined. 
is the area between a 50 and 125 mile radius. In order to explain plant i's output price and quantity we will include variables that measure demand in both its primary and secondary service area and the cost characteristics of all rival plants whose service areas overlap with plant i's. We include information on both primary and secondary service areas because we do not know the exact area served by each plant and this is one way to allow the data to identify the relevant area over which the firm competes. Most plant sales should fall in the primary service area and so we would expect that, if interdependence exists, a plant's price will be more heavily affected by the rivals in its primary service area rather than its secondary service area. The regression coefficients are allowed to differ for the two service areas to capture this possibility.

To identify the primary and secondary service areas empirically we rely on geographic information collected by the U.S. Census Bureau. The Census of Manufactures identifies the county and "place" in which each plant is located. ${ }^{17}$ They also construct the longitude and latitude at the population centroid for each county and place. Using this geographic information it is possible to locate all other places and counties whose population center lies within a specified radius of the county or place of interest. We measure the plant's primary service area to consist of all places whose population center is within a 50 mile radius of the population center for the place in which the plant is located. The secondary service area consists of all places whose population center is within a 50 to 125 mile radius of the center of the place in which the plant is located.

We define two groups of potential rival producers for each plant. The first group, or primary rivals, consist of all plant's whose primary service

17 The plant's "place" is a more disaggregated geographic identifier than the county and roughly corresponds to the city or town in which the plant is located. There are 10,132 different places, compared with 3149 counties, identified in the census data. 
area overlaps with any part of the plant's primary service area. These are identified as all plants located in places whose population center is within 100 miles of the center of the place in which the plant of interest is located. Similarly the group of secondary rivals is defined as all plants whose secondary service area overlaps with the secondary service area of the plant, that is all plant's located in places whose population center is between 100 and 250 miles of the center of the place in which the plant is located.

It is important to note how this process of market definition differs from the approach used in most studies of geographic markets. We do not define specific geographic markets and then attempt to explain price formation within that area as a function of the number of producers in the area. Instead we define service areas for each plant and then attempt to explain the plant's observed price as a function of the number and characteristics of the other plants that could also supply this service area. By defining both primary and secondary service areas we recognize that close rivals are more likely to compete directly with the plant and thus more likely to affect the output price observed in the census data.

Once the set of primary and secondary rivals are defined for each plant we construct summary measures of them. The number of primary and secondary rivals are included as two explanatory variables in the reduced form regressions. ${ }^{18}$ To account for rival firm costs the total capital stocks of primary and secondary rivals are included as explanatory variables. We also include weighted averages of the rival plant production worker wage rate, price of flour, price of energy, and price of other materials for both primary and secondary rivals. In all cases each primary rival's factor prices are weighted by their share of primary rival capital stock. Similarly, each

18 The set of rivals includes all bread or roll producers within the service area and not just the plants included in our sample. 
secondary rival is weighted by their share of the capital stock of all secondary rivals.

The Census Bureau also collects detailed information on population and income at the county level and we use this to construct plant-level demand variables. Demand characteristics of the primary and secondary service areas are measured using the population and per-capita income in the counties that fall in these service areas. Population is measured by summing the population of all counties in the service area. Per-capita income is measured as the share-weighted sum of the per-capita income of each county included in the service area. The share weights are population shares.

\section{Empirical Results}

\section{A. Basic Reduced-Form Model}

Summary measures of the plant output prices, disaggregated by the number of rival plants in their primary service area, are presented in Table 1 . The mean prices of bread and rolls and the standard errors of the means are reported. The mean price of bread declines from 37.7 cents per pound to 31.7 cents per pound as the number of rivals increases from zero to five. Beyond five competitors the mean price of bread rises with further increases in the number of rival producers. The same pattern is evident in the price of rolls. The price declines from 40.3 cents per pound to 36.5 cents per pound as the number of competitors increases from zero to two. Beyond that the price of rolls rises with further increases in the number of rivals until it reaches a high of 50.6 cents per pound for the largest category, more than 100 rivals. While Table 1 reveals some evidence that plants that face a small number of rivals have lower prices than plants that face no rivals, there is no evidence of a monotonic relationship between the plant's price and the number of rival producers it faces. 
The trend in prices revealed in Table 1 is likely to reflect trends in plant-level production costs. To see if costs exhibit a similar pattern with respect to the number of rivals the last column of Table 1 reports the mean of the plants' average variable cost disaggregated by the number of rivals. ${ }^{19}$ The mean of average variable cost exhibits the same pattern as the mean output prices. It declines from 27.7 cents per pound for plants that face no rivals to 24.7 cents per pound for plants that face five rivals. Beyond that point average variable cost rises to 32.3 cents per pound for the largest rival category. Thus much of the pattern in output prices seems to reflect the pattern in average variable cost.

One final point to notice in Table 1 concerns the number of competitors. In the case of bread, of the 624 plants in the sample 471 of them have at least 10 other bread-producing plants whose primary service area overlaps with their own. Only 13 plants have no other producers that overlap with their primary service area. While this may indicate that our definition of the primary service area is too large, it is useful to note that most of the

19 Variable cost is the sum of the plant's expenditure on labor, both wages and supplemental labor costs, and material inputs, including flour, sugar, yeast, fat and oils, and electricity. Because most plants produce multiple products, including bread and rolls and often other baked goods like cakes or pies, it is not possible to clearly define a measure of total plant output or average variable cost. In this case we assume that bread and rolls are perfect substitutes and add the physical quantity of each to produce a single output measure. We do not have physical quantity measures for the other baked goods produced in the plant, however, we must attempt to control for them when constructing a measure of plant output. We use the proportion of a plant's value of shipments that is accounted for by bread and rolls to scale up the quantity of bread and rolls into a total output measure. In effect this uses the weighted price of bread and rolls in the plant as a deflator for the value of shipments of other baked goods which are then summed with the quantity of bread and rolls to construct plant output. This procedure only affects the average variable cost measure used in this paper. This problem could be avoided by estimating a full structural model of the production and pricing decision that would include estimation of the multiproduct cost function. From this, product-specific estimates of marginal cost could be constructed for each plant and compared with the plant's prices. 
plants in our sample will face a fairly substantial number of rival producers. ${ }^{20}$

In order to control for both cost and the number of competitors as determinants of a plant's output price and level we estimate the reduced-form equations. The explanatory variables are divided into three groups; the plant's own cost variables, the number and cost characteristics of the rival producers in the plant's service area, and the demand characteristics. Because we cannot measure the characteristics of rivals for the thirteen plants that have no competitors in their primary service area these plants are not used when estimating the reduced-form regressions. ${ }^{21}$ The parameter estimates are reported in Tables 2 and 3. To simplify the results, we only report them for the regressions that just include the primary group of plant rivals rather than both the primary and secondary groups. When the secondary group of rivals are included all of their coefficients are individually and jointly insignificant and their inclusion had no effect on the reported results for the other variables.

Focusing first on the price regressions, some clear patterns emerge. Of the three groups of variables the only one with any statistically significant effect on either output price is the group of own cost variables, particularly the plant's own capital stock, factor prices, and product dummies. None of the rival plant characteristics, including the number of rival plants, and

20 In their studies of the competitive effects of entry using isolated geographic markets, Bresnahan and Reiss (1987, 1991) find evidence of an increase in the competitiveness of the market as the number of producers increases from one to two or three. They find very little additional competitive effects of entry once there are approximately three producers in most markets. If that pattern characterizes competition in the bread industry then most of our sample observations will be well beyond the point where an increase in the number of competitors will have any effect on output price.

21 A few additional plants are deleted because some variables are not reported. The sample used to estimate the regressions contains 608 bread producing plants and 564 roll producers. 
neither of the demand variables are statistically significant in either reduced-form price regression.

Among the plant's own cost variables, the capital stock has a significant negative effect in both price regressions. This is consistent with higher capital stocks reducing short-run or variable costs and thus prices in competitive markets. The wage rates for production workers have a statistically insignificant effect on prices. Nonproduction worker wages have a negative effect on the output price of both products and the coefficient in the bread equation is statistically significant. The negative coefficient is surprising since higher factor prices will result in higher output prices under most market structures. The most likely explanation is that the observed wage rates for non-production workers reflect differences in worker quality. ${ }^{22}$ If the plants that pay higher wages also purchase higher-quality labor inputs then they may actually have lower average variable costs, and thus prices, then their low-wage counterparts. The prices of the major intermediate inputs, flour and other materials, have the expected positive sign in the price regressions. ${ }^{23}$ The dummy variables that reflect the mix of seven-digit products produced in the plant are often statistically significant. In the bread equation, plants that produce specialty products, like raisin bread, have higher average bread prices. Similarly, in the roll equation, plants that produce specialty products or hearth rolls have higher

22 A very robust finding in the labor literature is that wage rates rise with plant size and, in their review of the empirical studies, Brown and Medoff (1989) report that differences in worker quality is the most likely explanation.

23 The price of electricity also has a negative coefficient in the price regressions and it is statistically significant in the rolls equation. This could result if plants that face high electricity prices use other fuels, such as natural gas, to run the baking ovens. To check this possibility we estimated the model on a subset of the plants for which natural gas prices were available. Even after controlling for the gas price, the coefficient on the price of electricity remained negative. 
average roll prices. ${ }^{24}$ The remaining plant characteristics, age and the

dummy variable for multiple plant ownership, are not statistically

significant.

Individually none of the coefficients measuring the effect of the plant's rivals in its primary service area or the demand conditions are statistically significant. The coefficient on the number of rival producers is negative in the equation for the price of bread but posititive in the rolls equation. In both cases the coefficients are very small and they are far from statistically significant. The first column of table 4 reports the test statistics for the hypothesis that the coefficients on the rival plant variables are jointly equal to zero. The test statistic takes the value .692 in the bread price regression and .796 in the roll price regression. In both cases we do not reject that rival producers have no effect on the plant's output prices. ${ }^{25}$

The last three columns of table 4 report test statistics for the hypotheses that the characteristics of the plant's primary and secondary rivals jointly have no effect (column 2), that the demand characteristics jointly have no effect (column 3), and that primary rivals, secondary rivals, and demand characteristics jointly have no effect (column 4). In each of these three

24 There is also some mixed evidence on the presence of economies and diseconomies of scope. Plants that produce hamburger rolls have lower bread prices, but plants that produce hearth rolls have higher bread prices. This may reflect specialization of some plants into high-volume, low-value products such as white pan bread and hamburger rolls, while other plants produce higher-valued specialty bread and roll products.

25 This does not result from multicollinearity between the own and rival variables. Within the sample the factor prices faced by a plant are not highly correlated with the average factor prices faced by the rival producers in their primary service area. For example, the simple correlation between the own and rival price of flour is only .064 in the sample. The simple correlations for the own and rival wage rates, electricity prices, and material prices are.297,.353, and .055, respectively. To further check the possibility that the finding is driven by an inability to precisely discriminate between own and rival cost variables, we reestimated the model after deleting all the own cost variables. Even in this case we cannot reject the hypothesis that the rival variables jointly have no effect on the plant's output price or quantity. 
cases the unrestricted model contains the variables for both primary and secondary rivals. The only hypothesis that is rejected is that the price of rolls is unaffected by primary rivals, secondary rivals, and demand conditions. However, as reported in columns 2 and 3, we cannot reject that both the rival variables and demand variables alone have no effect.

Overall, the reduced-form price regressions reveal a simple pattern. Large plants, as measured by capital stock, and plants with lower prices for their raw materials, particularly flour, have lower output prices for both bread and rolls. The number of rival plants in the primary and secondary service area, the cost conditions of those rivals, and the demand characteristics in the primary and secondary service area have no effect on output prices. The results are inconsistent with a general model of oligopolistic competition or monopoly.

These conclusions are also supported by examining the reduced-form regressions for the outputs of bread and rolls, reported in Table 3 . In the output regressions only the coefficients for the plant's own cost variables are statistically significant. Among the plant's cost variables the pattern of coefficients is simple. Larger plants, measured by capital stock, plants with higher wages, older plants, and plants owned by multi-plant firms have larger output levels of both products. Plants with higher prices for intermediate inputs, including flour, electricity, and other materials, have smaller quantities of output. Most of these coefficients are statistically significant. The product dummies indicate that the bread plants producing white pan, rye, and wheat breads tend to be significantly larger than plants producing hearth breads and specialty products. There are no significant size differences, with variation in the mix of outputs produced, among the roll producers.

Coefficients for the rival plant characteristics and demand characteristics are not individually different from zero. Test statistics 
reported in Table 4 also reveal that the coefficients on the rival and demand characteristics are not jointly different from zero.

Overall the reduced-form price and quantity regressions do not provide any support for short-run oligopolistic competition among plants with differentiated products in the bread industry. The quantity equations indicate that variations in output levels are determined by differences in the plant's own cost variables, as would be the case for plants that acted as price-takers in the output market. The price equations indicate that there is plant-level variation in output prices and that this variation is correlated with plant production costs and product mix, but not with demand or rival producer characteristics. This is consistent with the view that each plant produces a different bundle of bread products but that the demand elasticity they face is very high.

Given the finding that prices and output levels are primarily determined by a producer's own costs it is useful to examine the reduced-form regression for the plant's average variable cost. Do the exogenous variables that imply lower output prices also imply lower average cost? The reduced-form regression for the log of average variable cost is reported in the last column of Table $3 .{ }^{26}$ Focusing on the significant coefficients, the results indicate that a higher capital stock and a lower flour price reduce average cost as expected. Both factors also lead to significantly lower output prices. The product-mix dummy variables also reveal a clear pattern. Plants that produce wheat bread have lower average costs and plants that produce specialty breads, hearth rolls, and specialty rolls have higher average costs. These cost differences are identical to the pattern of price differences among products reported above. In addition, none of the rival cost variables or demand

26 As described in footnote 19, this assumes that bread and rolls are perfect substitutes and the quantities of each can be summed into a single output measure. 
variables are significantly correlated with the plant's production costs. Overall, the pattern of plant-level average cost variation closely mirrors the variation in output prices.

\section{B. Alternative Model Specifications}

The results reported in Tables 2 and 3 are based on a model that assumes the price of output is a linear function of the number of potential rival firms. We estimate two additional models to check the sensitivity of our finding that the number of rivals has no effect on price. The first allows for a (piecewise) nonlinear relationship between the output price and the number of rivals by replacing $\mathrm{N}$ in the regression equations with a set of dummy variables for the number of rivals. The second limits the sample of plants to those that face 10 or fewer rivals. The findings of Bresnahan and Reiss (1991) indicate that in several service industries an increase in the number of firms results in increased competition, but only when there are a small number of firms. By limiting the sample to plants that face 10 or fewer rivals we focus directly on the plants in which an increase in the number of rivals is most likely to have a negative effect on price.

To allow for a nonlinear relationship between the number of rivals and output price we include a set of seven dummy variables to distinguish the number of rival producers. Rather than report a separate table of results, we will briefly describe the results of these regressions. In the regressions for the price of bread, the dummy-variable coefficients indicate that, relative to the base group of plants with 1 or 2 rivals, increases in the number of rivals have a negative effect on price. However, of the individual coefficients none are statistically significant at the .05 level and only the one for the group of plants with 3 to 5 rivals is significant at the .10 level. We cannot reject the hypothesis that the dummy-variable coefficients are jointly equal to zero. The evidence from the regressions for the price of 
rolls is even less striking. None of the dummy-variable coefficient are individually or jointly different than zero. ${ }^{27}$

Limiting the sample to plants with 10 or fewer rivals also has no

substantial effect on the reported results. In the runs which include the number of rivals $\mathrm{N}$ as the explanatory variable we cannot reject the hypothesis that all rival variables are jointly equal to zero in the price, quantity, and average cost regressions. Overall, these checks on the regression specification support the earlier findings that the number and cost characteristics of rivals have no significant effect on the price or quantity of bread and rolls at the plant level.

An additional robustness check involves a redefinition of the output category. Rather than defining the output of bread as the sum of the five seven-digit product categories, we focus only on the one seven-digit product, white-pan bread, that accounts for the majority of industry output. We estimated the basic reduced-form model given in equation 5 using the plant's output and price for white-pan bread as the dependent variables. Again we do not reject the hypotheses that rival variables and demand variables jointly have no effect the price or quantity of output. The regression coefficients for the own cost variables are the only ones significant in these regressions and the coefficients are very similar to those reported in Tables 2 and 3 . We conclude that our finding of no interdependence among producers is robust to the product definitions used.

While the focus of this study has been on plant-level factors, as a final check we examine if there is any systematic firm-level variation in the prices of the outputs. As reported in Tables 2 and 3, dummy variables for

27 We also cannot reject the hypothesis that the dummy variable coefficients are jointly equal to zero in the regressions for the quantity of bread and quantity of rolls. We do reject that they are all equal in the regressions for average variable cost. In the latter case the pattern of coefficients indicates significantly lower average cost for the group of plants with 3 to 5 rivals. 
multiple-plant ownership are not significant in the output price and average variable cost regressions but are significant in the quantity of bread regression. These indicate that plants owned by multi-plant firms, which include the national and regional producers, are larger, but have similar average variable cost and prices to single-plant producers.

To explore the possible importance of firm effects further, dummy variables are included in the output price regressions to distinguish the fifteen firms with the largest number of plants in the sample. These are the major national and regional bread manufacturers. Of the fifteen firm coefficients that are estimated, approximately half are negative and half are positive. Several of the coefficients are statistically significant and we reject the hyptheses that they are jointly equal to zero in the output price

regressions. In the equations for the quantity of output we do not reject the hypotheses that the firm effects are jointly equal to zero. Overall, these results suggest that there are no firm-specific differences in the size of bread manufacturing plants but that there are firm differences in the prices of bread and rolls. The prices charged by the major producers, however, are not uniformly higher or lower than those charged by the smaller producers.

\section{v. Summary and Conclusions}

This paper uses micro data for U.S. bread manufacturing plants in 1977 to study the relationship between the plant's output price, its own production costs, and the nature of demand and the cost characteristics of other manufactures in its service area. The results indicate that both the quantity of bread and rolls produced, as well as their prices, vary systematically with the plant's own cost variables, particularly its capital stock and the prices of important raw materials. Variables representing demand characteristics in the plant's service area and variables representing the number and production 
costs of rival producers do not have statistically significant effects on either the plant's output prices or quantities. The results are not consistent with either monopoly pricing or oligopolistic competition among bread producers. They appear most consistent with a model of price-taking behavior by individual producers combined with output-quality differentials across producers.

One factor that we cannot explore with a single cross-section of plants, but that is likely to be important in explaining these results, is the ease of entry into this industry. If the sunk costs of entry are uniformly low across the observations in the data then the actual number of competitors should be irrelevant in explaining variation in output prices. The fact that output prices are only determined by the plant's own costs, regardless of the number or characteristics of other suppliers that can sell in the service area, suggests that easy entry may be an important constraining factor for producers in this industry. In the bread industry, entry can occur not only from new plants but from existing plants that alter the mix of outputs they produce and from existing plants that alter the geographic area they service. The possibility of entry from all three of these sources may be sufficient to constrain the pricing behavior of the incumbent producers. 
Table 1

Summary Statistics: Output Prices and Average Variable Cost (standard error of the mean in parentheses)

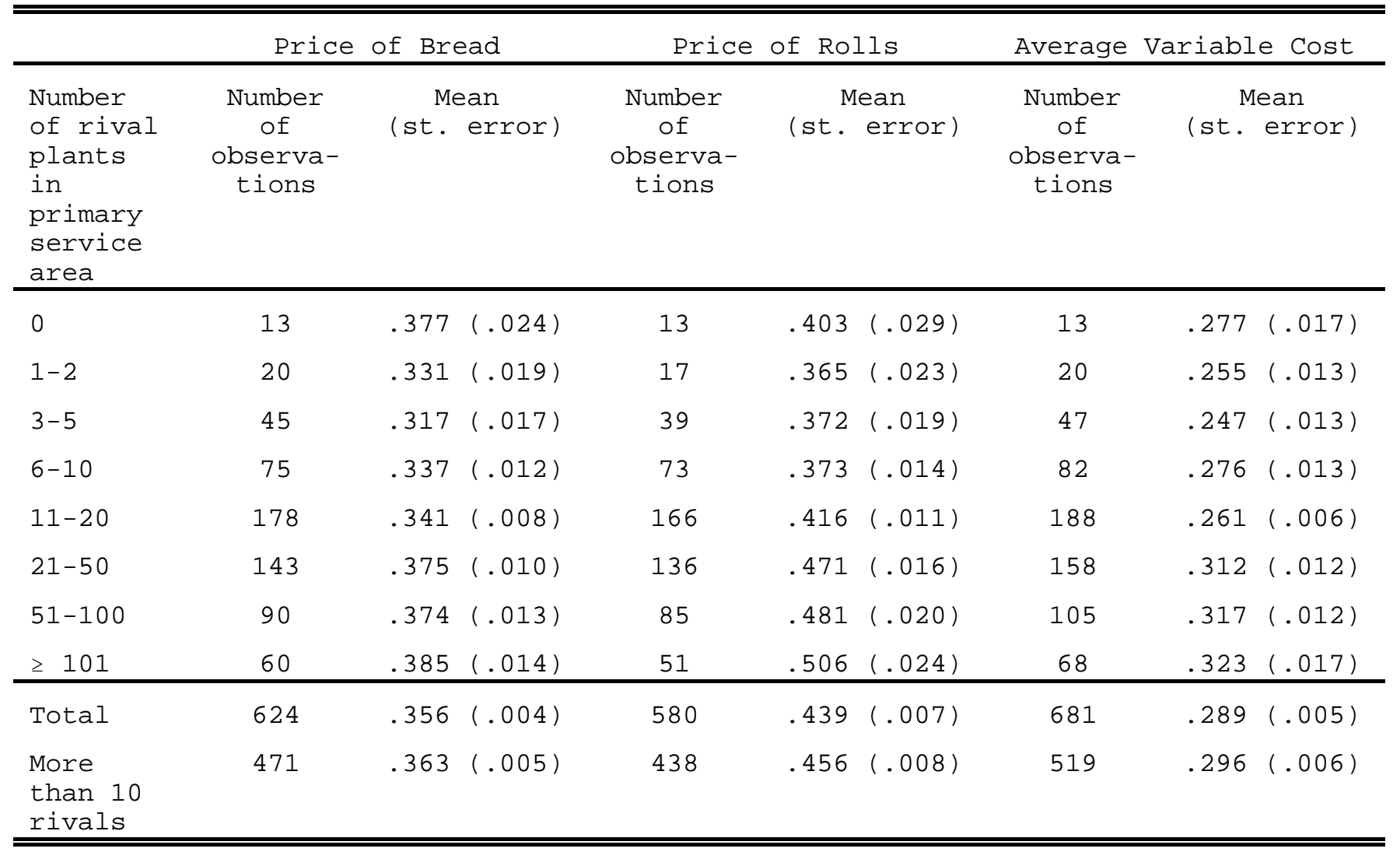

Prices and average variable cost measured as $\$$ per 1 b. 
Tabl e 2

Coeffici ents for Reduced Form Price Equati ons

( st andard errors i $n$ parent heses)

\begin{tabular}{|c|c|c|}
\hline & Log Price Bread & Log Price Rol Is \\
\hline I nt ercept & $-2.295(1.041)^{*}$ & $-3.040(1.282)^{*}$ \\
\hline \multicolumn{3}{|l|}{ Own PI ant Characteristics } \\
\hline $\log K$ & $-.029(.006)^{*}$ & $-.020(.008)^{*}$ \\
\hline $\log W$ & $.006(.038)$ & $-.026(.047)$ \\
\hline $\log W_{P}$ & $-.068(.026)^{*}$ & $-.050(.030)$ \\
\hline $\log w$ & $.136(.037)^{*}$ & $.132(.042)^{*}$ \\
\hline $\log w$ & $-.006(.037)$ & $-.135(.047)^{*}$ \\
\hline $\log W_{h}$ & $.043(.020)^{*}$ & $.031(.023)$ \\
\hline Age 1 & $.037(.049)$ & $.079(.055)$ \\
\hline Age 2 & $-.042(.044)$ & $-.038(.049)$ \\
\hline Age 3 & $-.036(.043)$ & $065(.055)$ \\
\hline Mul tiple pl ant dumy & $.014(.030)$ & $070(.037)$ \\
\hline \multicolumn{3}{|l|}{$\begin{array}{l}\text { Product } \mathrm{cl} \text { ass } \\
\text { dummi es }\end{array}$} \\
\hline B1 Wite Pan & Base cat egor y & $.005(.042)$ \\
\hline B2 Hearth & $-.009(.024)$ & $.013(.031)$ \\
\hline B3 Wheat & $-.032(.029)$ & $.003(.037)$ \\
\hline B4 Rye, Pump. & $-.015(.028)$ & $-.111(.035)^{*}$ \\
\hline B5 Speci al ty & $.094(.025)^{*}$ & $.064(.031)^{*}$ \\
\hline R1 Hamb, Hot Dog & $-.056(.027)^{*}$ & Base cat egory \\
\hline R2 B. Serve & $-.031(.025)$ & $-.001(.029)$ \\
\hline R3 Muffins & $.044(.036)$ & $-.027(.038)$ \\
\hline R4 Hearth & $.132(.034)^{*}$ & $.190(.039) *$ \\
\hline R5 Speci al ty & $.017(.025)$ & $.078(.029)^{*}$ \\
\hline R6 St uf f ing & $-.002(.032)$ & $.034(.036)$ \\
\hline \multicolumn{3}{|l|}{$\begin{array}{l}\text { Pri mary Ri val } \\
\text { Characteri stics }\end{array}$} \\
\hline $\mathrm{N}$ & $-.001(.001)$ & $.0001(.0007)$ \\
\hline $\log K$ & $.015(.016)$ & $.007(.020)$ \\
\hline $\log W_{6}$ & $.091(.093)$ & $.056(.119)$ \\
\hline $\log w$ & $.063(.069)$ & $.015(.084)$ \\
\hline $\log W_{t}$ & $.041(.067)$ & $.131(.079)$ \\
\hline $\log W_{h}$ & $-.005(.035)$ & $.034(.043)$ \\
\hline \multicolumn{3}{|l|}{ Demand Char act eri sti cs } \\
\hline Popul at i on & $.013(.021)$ & $.023(.026)$ \\
\hline Per - Capi t a I ncome & $.031(.132)$ & $.140(.162)$ \\
\hline Sampl e si ze & 611 & 567 \\
\hline$R^{2}$ & .220 & .238 \\
\hline
\end{tabular}


Mean Dep. Var. $\hat{F}$
- 1. 077

.252
$-.880$

.291

Al I regressions incl ude dumy variables to distingui sh ni ne census geographic regi ons. 
Tabl e 3

Coeffici ents for Reduced Form Quantity and

Average Variabl e Cost Equations

I nt ercept

Onn Pl ant

Char act er i st i cs

$\log K$
$\log W_{W}$
$\log W_{p}$
$\log W_{k}$
$\log W_{t}$
$\log W_{h}$
Age 1
Age 2
Age 3
Mul ti pl e pl ant

dummi es

Product $\mathrm{cl}$ ass

B1 Whi te Pan

B2 Hearth

B3 Wheat

B4 Rye, Pump.

B5 Special ty

R1 Hamb, Hot Dog

R2 B. Serve

R3 Muffins

R4 Hearth

R5 Special ty

R6 Stuffing

Pri mary Ri val Char act eri sti cs

$\mathrm{N}$

$\log K$

$\log W_{6}$

$\log W_{k}$

$\log W_{k}$

$\log W_{h}$

Demand Characteri st i cs

$$
\begin{array}{r}
.004(.002) \\
-.050(.061) \\
.199(.348) \\
.130(.268) \\
-.198(.246) \\
-.213(.131)
\end{array}
$$

\begin{tabular}{|c|c|}
\hline $.357(.030)^{*}$ & $-.027(.007)$ \\
\hline $.064(.174)$ & $-.052(.043)$ \\
\hline $.513(.110)^{*}$ & $014(.029)$ \\
\hline
\end{tabular}

$-.831(.154)^{*} \quad .190(.041)^{*}$

$-.081(.173)^{*} \quad-.006(.043)$

$-.016(.085) \quad .015(.021)$

$-.276(.201) \quad .050(.055)$

$-.140(.181) \quad-.066(.048)$

$-.541(.201)^{*} \quad-.005(.050)$

$.017(.135) \quad-.037(.035)$

$\begin{array}{rr}.096(.156) & \text { Base cat egory } \\ -.214(.113) & .007(.028) \\ -.084(.137) & -.085(.035)^{*} \\ .239(.128)^{*} & -.022(.034) \\ -. .334(.115)^{*} & .086(.030)^{*} \\ \text { Base cat egory } & -.030(.031) \\ .187(.107) & .002(.030) \\ .189(.141) & -.023(.040) \\ -.037(.145) & .227(.040)^{*} \\ -.145(.105) & .073(.029)^{*} \\ .064(.131) & .034(.037)\end{array}$

Popul at i on

$-.001(.079)$

Per-Capi ta I ncome

$-.083(.096)$

$.024(.025)$

$\begin{array}{rr}.005(.003) & -.001(.001) \\ .020(.072) & .004(.019) \\ -. .439(.411) & .006(.110) \\ .016(.308) & .072(.082) \\ -.024(.291) & .044(.078) \\ -.085(.158) & .080(.042)\end{array}$

$-.220(.596) \quad-.081(.158)$ 


$\begin{array}{crrr}\text { Sampl e size } & 611 & 567 & 665 \\ R^{2} & .636 & .497 & .234 \\ \text { Mean Dep. Var. } & 8.952 & 8.046 & 1.308 \\ \hat{F} & .941 & 1.067 & .308\end{array}$

Al I regressi ons i ncl ude dumy variables to distingui sh ni ne census geographic regi ons. 
Table 4

Hypothesis Tests:

Values of the F-statistic

\begin{tabular}{|c|c|c|c|c|}
\hline $\begin{array}{l}\text { Dependent } \\
\text { Variable }\end{array}$ & $\begin{array}{c}\text { No Effect of } \\
\text { Primary } \\
\text { Rivals }\end{array}$ & $\begin{array}{c}\text { No Effect of } \\
\text { Primary or } \\
\text { Secondary } \\
\text { Rivals }\end{array}$ & $\begin{array}{l}\text { No Demand } \\
\text { Effects }\end{array}$ & $\begin{array}{c}\text { No Rival or } \\
\text { Demand } \\
\text { Effects }\end{array}$ \\
\hline $\begin{array}{l}\text { Log price } \\
\text { bread }\end{array}$ & .692 & 1.177 & .433 & 1.112 \\
\hline $\begin{array}{l}\text { Log price } \\
\text { rolls }\end{array}$ & .796 & 1.378 & 1.266 & $2.096^{*}$ \\
\hline $\begin{array}{l}\text { Log quantity } \\
\text { bread }\end{array}$ & 1.081 & .883 & .438 & .856 \\
\hline $\begin{array}{l}\text { Log quantity } \\
\text { rolls }\end{array}$ & .992 & 1.261 & 1.119 & 1.250 \\
\hline $\begin{array}{l}\text { Log average } \\
\text { variable cost }\end{array}$ & .922 & 1.087 & .385 & 1.145 \\
\hline $\begin{array}{l}\text { Number of } \\
\text { restrictions }\end{array}$ & 6 & 12 & 4 & 16 \\
\hline
\end{tabular}

${ }^{*}$ Reject hypothesis at .05 significance level. 
Abbott, Thomas A., "Price Dispersion in U.S. Manufacturing: Implications for the Aggregation of Products and Firms," Graduate School of Management, Rutgers University, Working Paper, 1991.

Block, Michael Kent and James Clabault, Sherman Act Indictments 1955-1980, New York: Federal Legal Publications, 1981.

Block, Michael Kent, Frederick Carl Nold, Joseph Gregory Sidak, "The Deterrent Effect of Antitrust Enforcement, Journal of Political Economy, 89(3), June 1981, 429-444.

Borenstein, Severin, "Hubs and High Fares: Dominance and Market Power in the U.S. Airline Industry," Rand Journal of Economics, 20 (3), Autumn 1989, $344-368$.

Borenstein, Severin and Nancy L. Rose, "Competitive Price Discrimination in the U.S. Airplane Industry," Discussion Paper, Institute of Public Policy Studies, University of Michigan, 1989.

Bresnahan, Timothy, "Empirical Studies of Industries With Market Power," in Richard Schmalensee and Robert Willig (eds.), Handbook of Industrial Organization, Amsterdam: North Holland, 1989, 1011-1057.

Bresnahan, Timothy and Peter Reiss, "Do Entry Conditions Vary Across Markets?" Brookings Papers on Economic Activity, 3, 1987, 833-871.

Bresnahan, Timothy and Peter Reiss, "Entry and Competition in Concentrated Markets," Journal of Political Economy, 99(5), October 1991, 977-1009.

Brown, Charles and James Medoff, "The Employer Size-Wage Effect," Journal of Political Economy, 97 (5), October 1989, 1027-1059.

Demsetz, Harold, "Industry Structure, Market Rivalry, and Public Policy," Journal of Law and Economics, $16(1)$, April 1973, 1-10.

Dixit, Avinash, "Comparative Statics for Oligopoly," International Economic Review, 27 (1), February 1986, 107-122.

Dunne, Timothy, Mark J. Roberts, and Larry Samuelson, "The Growth and Failure of U.S. Manufacturing Plants," Quarterly Journal of Economics, 104(4), November 1989, 671-698.

Garber, Steven and Steven Klepper, "Relative Price Changes in Recession: A Microeconometric Analyses of U.S. Manufacturing," International Economic Review, $27(1)$, February 1986, 187-208.

Garber, Steven and Steven Klepper, "'Administered Pricing' or Competition Coupled with Errors of Measurement?" International Economic Review, $21(2)$, June $1980,413-435$.

Kreps, David and Jose Scheinkman, "Quantity Precommitment and Bertrand Competition Yield Cournot Outcomes," Bell Journal of Economics, 14 (2), Autumn 1983, 326-337. 
Panzar, John C. and James N. Rosse, "Testing for 'Monopoly' Equilibrium," Journal of Industrial Economics, 35(4), June 1987, 443-456.

Schmalensee, Richard, "Inter-Industry Studies of Structure and Performance," in Richard Schmalensee and Robert Willig (eds.), Handbook of Industrial Organization, Amsterdam: North Holland, 1989, 951-1009.

Sutton, John, Sunk Costs and Market Structure, Cambridge, MA: MIT Press, 1991 .

Weiss, Leonard W., Concentration and Price, Cambridge, MA: MIT Press, 1991.

Werden, Gregory J., "A Review of the Empirical and Experimental Evidence on the Relationship Between Market Structure and Performance," Discussion Paper, Economic Analysis Group, U.S. Department of Justice, 1991. 